\title{
ANALISIS PENGAWASAN PUNGUTAN RETRIBUSI PASAR TERHADAP KINERJA PEGAWAI RETRIBUSI
}

\author{
Tiar Mirnasari $^{(1)}$, Yuliana Yamin ${ }^{(2)}$ \\ Fakultas Ekonomi Universitas Sang Bumi Rua Jurai \\ tiarmirnasari2021@gmail.com, yuliyamin0607@gmial.com
}

\begin{abstract}
Abstrak. Penelitian ini bertujuan untuk menganalisis pengawasan pungutan retribusi pasar terhadap kinerja pegawai retribusi di kantor dinas pasar kota bandar Lampung. Objek penelitian adalah di kantor dinas pasar kota Bandar lampung. Jenis penelitian yang digunakan adalah kuantitatif deskriptif dengan uji analisis regresi linear berganda. Metode pengumpulan data yang digunakan adalah data primer. Teknik pengumpulan data yang digunakan adalah observasi, kusioner dan telaah dokumentasi atau kepustakaan. Berdasarkan analisis data dalam penelitian ini dapat disimpulkan bahwa terdapat pengaruh antara variabel Pengawasan Pungutan Retribusi terhadap Kinerja Pegawai Retribusi sehingga ha dapat diterima.
\end{abstract}

Kata Kunci: Pengawasan, Pungutan Retribusi Pasar, Kinerja Pegawai

\begin{abstract}
This study aims to analyze the supervision of market levies on the performance of retribution employees at the market office of Bandar Lampung city. The object of research is at the Bandar Lampung city market office. The type of research used is descriptive quantitative with multiple linear regression analysis test. The data collection method used is primary data. Data collection techniques used are observation, questionnaires and documentation or literature review. Based on the analysis of the data in this study, it can be said that there is an influence between the Supervision of Levy Collection on the Performance of Retribution Employees so that it can be accepted.
\end{abstract}

Keywords: Supervision, Market Levies, Employee Performance

\section{PENDAHULUAN}

Kota Bandar Lampung merupakan salah satu daerah otonomi dan salah satu penyelenggara pemerintahan daerah yang menganut prinsip otonomi nyata dan bertanggung jawab, dalam arti pemberian otonomi kepada daerah harus berdasarkan kepada faktor-faktor, perhitunganperhitungan dan kebijaksanaankebijaksanaan yang benar-benar sejalan dengan tujuannya, yaitu melancarkan pembangunan yang tersebar luas diseluruh pelosok dalam rangka meningkatkan taraf hidup dan kecerdasan serta kesejahteraan rakyatnya.
Retribusi (Putriani and Parjiyana 2017) adalah suatu pembayaran atas penyediaan fasilitas pasar traditional/sederhana yang berupa pelataran lokasi/kios yang di berikan dan atau dikelola oleh pemerintah daerah untuk kepentingan serta dapat dinikmati oleh orang pribadi atau badan, maka di pungut retribusi atas jasa pelayanan baik kebersihan dan persampahan

Retribusi jasa usaha (Elim, Saerang, and Toduho 2014) yaitu retribusi atas jasa yang disediakan oleh pemerintah daerah dengan menganut prinsip komersial karena pada dasarnya dapat pula disediakan oleh 
sektor swasta jenis retribusi ini salah satunya adalah retribusi pasar.

Retribusi pasar (Putriani and Parjiyana 2017) adalah pungutan yang dilakukan kepada pengguna jasa fasilitas dan prasarana pasar. Jasa tersebut diberikan kepada oleh pemerintah daearah kepada pengguna jasa fasilitas dan prasarana pasar. Hal ini tertuang dalam Peraturan Daerah kota Pekanbaru Nomor 6 tahun 2012 tentang retribusi pelayanan pasar bahwa retribusi pelayanan pasar adalah setiap pelayanan dan penyediaan fasilitas pasar yang dikelola pemerintah kota, di pungut retribusi dengan nama retribusi pelayanan pasar

Retribusi Pasar sebagai salah satu sumber pendapatan asli daerah di Kota Bandar Lampung dan dikelola oleh Dinas Pasar. Retribusi Pasar ini di Kota Bandar Lampung mempunyai peranan yang penting dalam Anggaran Pendapatan dan Belanja Daerah

Retribusi daerah (Mafaza, Mayowan, and Sasetiadi 2016)adalah pembayaran wajib oleh orang pribadi atau badan atas disediaakannya jasa tertentu oleh pemerintah dan mendapatan timbal balik secara langsung.

Sesuai dengan Undang-Undang Nomor 23 Tahun 2014 tentang PokokPokok Pemerintahan di Daerah disebutkan sebagai berikut "Tujuan pemberian otonomi kepada Daerah adalah untuk memungkinkan Daerah yang bersangkutan mengatur dan mengurus rumah tangganya sendiri untuk meningkatkan daya guna dan berhasilguna penyelenggaraan pemerintahan dalam rangka pelayanan terhadap masyarakat dan pelaksanaan pembangunan.

Untuk dapat melaksanakan tujuan tersebut maka kepala daerah perlu diberikan wewenang untuk melaksanakan berbagai urusan pemerintahan sebagai urusan rumah tangganya sendiri agar supaya daerah dapat mengurus rumah tangganya sendiri dengan sebaik-baiknya maka kepada Daerah perlu diberikan sumber-sumber yang cukup melalui Subsidi perimbangan keuangan, namun tidak semua sumber pembiayaan dapat diberikan kepada Daerah. Oleh karena itu Daerah diwajibkan untuk dapat menggali segala sumber Keuangan sendiri berdasarkan Peraturan-Peraturan dan Kebijaksanaan-Kebijaksanaan serta Undang-Undang yang berlaku di Negara Indonesia.

Untuk dapat menjamin penyelenggaraan Pemerintahan serta memajukan pembangunan di Daerah, maka perlu untuk meningkatkan pendapatan Daerah dengan pemungutan yang lebih efektif dan wajar terhadap penggalian sumber-sumber yang baru yang tidak bertentangan dengan kepentingan Nasional dan sesuai dengan perundangan yang berlaku.

Kinerja (Mustakim and Nur'aeni 2020) adalah suatu proses dimana seseorang dalam melaksanakan tugasnya memperoleh hasil yang dicapai sesuai dengan tanggung jawab yang diembannya.

Kinerja (Suprihati 2014)adalah pencapaian atas tujuan organisasi yang dapat terbentuk output kuantitatif maupun kualitatif, kreatifitas, fleksibilitas, dapat diandalkan atau hal-hal lain yang dapat diinginkan

Kinerja karyawan (Sukmarwati 2013) adalah hasil kerja secara kualitas dan kuantitas yang dicapai oleh seorang karyawan dalam melaksanakan tugasnya sesuai dengan tanggung jawab yang diberikan kepadanya

Dengan demikian dapat disimpulkan bahwa kinerja merupakan suatu proses pencapaian atas tujuan dalam menjalankan 
tugas sesuai dengan tanggung jawab yang diberikan.

Berdasarkan penelitian (Datu, Sabijono, and Najoan 2016) Sistem dalam pemungutan retribusi telah memadai karena unsur-unsur yang ada pada hasil penelitian juga terdapat pada teori pengendalian internal.

Penelitian sebelumnya (Rajab 2020) kontribusi retribusi pasar terhadap Pendapatan Asli Daerah di Kabupaten Mamuju selama periode tahun 2014 sampai dengan tahun 2018 berkisar antara 1,52\% sampai $1,1 \%$ dengan rata-rata kontribusi mencapai $1,29 \%$. Kontribusi retribusi pasar terhadap Pendapatan Asli Daerah terbesar terjadi pada tahun 2014 dengan kontribusi $1,52 \%$ dan kontribusi terkecil terjadi pada tahun 2017 dengan kontribusi 1,08\%.

Selanjutnya penelitian lain tentang optimalisasi retribusi pasar oleh (Alhaksbi 2015) menunjukan bahwa faktor-faktor yang mempengaruhi strategi Dinas Kebersihan, Pertamanan dan Pasar Badan Rokan Hilir untuk optimalisasi retribusi pasar untuk optimalisasi retribusi pasar minim koordinasi dengan instansi lain, meminimalkan sosialisasi peraturan, meminimalkan lembaga pengendali, penempatan staf lembaga dan meminimalkan insentif bagi staf retribusi.

Masalah Keuangan Daerah merupakan masalah yang sangat penting, terutama dengan makin meningkatnya tugas-tugas dan Kegiatan-kegiatan Daerah pada masa Pembangunan seperti sekarang ini, baik dalam pelayanan umum dan kesejahteraan masyarakat daerahnya, maupun dalam menghadapi tugas-tugas untuk melaksanakan Pembangunan Daerah masing-masing. Oleh karena itu Daerah harus mempunyai sumber-sumber pendapatan sendiri untuk dapat membiayai pembangunan di Daerahnya.

Berkenaan dengan keuangan daerah, dalam penjelasan umum Undang-Undang Nomor 23 Tahun 2014 antara lain menyebutkan pula agar daerah mengurus rumah tangganya sendiri dengan sebaikbaiknya. Jadi daerah mempunyai kewajiban untuk menggali sumber pendapatan asli Daerah sendiri, yang terdiri dari Pajak Daerah, Retribusi Daerah, hasil perusahaan daerah dan lain-lain hasil usaha daerah yang syah, yang diperlukan untuk mencukupi anggaran belanja rutin. Untuk itu daerah mempunyai tugas dan tanggung jawab agar senantiasa berusaha meningkatkan pendapatan daerah sendiri sebagai penunjang utama untuk meningkatkan kegiatan pelaksanaan pembangunan daerah.

Dalam rangka meningkatkan penerimaan daerah khususnya dari sektor retribusi pasar ini, maka diperlukan pengawasan yang intensif dari para petugas yang terkait serta koordinasi dan perencanaan yang mantap sehingga diharapkan peningkatan hasil yang benarbenar berjalan sebagaimana dengan tujuan yang telah direncanakan sebelumnya.

\section{METODE PENELITIAN}

Objek penelitian ini pegawai Dinas Pendapatan Daerah Kota Bandar Lampung.

Metode pengumpulan data yang digunakan dalam penulisan ini yaitu, data primer dan data sekunder.

\section{a. Data Primer}

Data primer merupakan data yang diperoleh langsung tanpa perantara orang atau lembaga lain sebagai pihak ketiga. Data primer ini 


diperoleh dengan wawancara
melalui responden
menggunakan daftar pertanyaan
dalam hal ini pegawai Dinas Pasar
bagian pungutan retribusi pasar.

b. Data Sekunder

Merupakan data yang diperoleh melalui orang lain yang berhubungan dengan permasalahan yang dipecahkan. Data sekunder ini diperoleh melalui cara studi dokumenter yaitu mengumpulkan adn mempelajari brosur-brosur serta dokumen-dokumen, catatan-catatan dan arsip perusahaan.

Teknik pengumpulan data pada penelitian ini menggunakan observasi, angket dan telaah dokumentasi.

Jenis penelitian yang digunakan dalam penelitian ini adalah kuantitatif deskriptif analisis menggunakan regresi linear sederhana. Dalam menganalisis secara kuantitatif penulis menggunakan rumus statistik yaitu rumus uji linear sederhana sebagai berikut :

$$
\begin{aligned}
& Y=a+b X+e \\
& Y=\text { Kinerja Pegawai } \\
& \mathrm{x}=\text { Pengawas Pungutan Retribusi } \\
& \mathrm{e}=\text { error }
\end{aligned}
$$

\section{Uji Hipotesis}

diuji dengan menggunakan uji $\mathrm{t}$ - student yang kemudian dibandingkan dengan besaran $\mathrm{t}$ - tabel dengan perumusan sebagai berikut :

$$
t o=r \sqrt{\frac{N-1}{\left(1-r^{2}\right)}}
$$

Keterangan :

$$
\begin{array}{ll}
\text { to } & =\text { Besarnya nilai } \mathrm{t} \text { observasi } \\
\mathrm{r} & =\text { Besarnya nilai koefisien korelasi } \\
\mathrm{N} & =\text { Banyaknya subjek (Populasi) }
\end{array}
$$

\section{HASIL DAN PEMBAHASAN}

Berdasarkan penelitian tentang analisis pengawasan pungutan retribusi pasar terhadap kinerja pegawai retribusi adalah sebagai berikut :

\section{Analisis Kualitatif}

\section{Uji Validitas}

Uji validitas dalam penelitian ini menggunakan korelasi produc moment ini menunjukan bahwa korelasi antara masingmasing indikator terhadap total skor konstruk dari setiap variabel menunjukkan hasil yang signifikan dan hanya satu pada variabel Pengawasan Pungutan Retribusi yang lebih kecil, sehingga menunjukkan bahwa $\mathrm{r}$ hitung $>\mathrm{r}$ tabel. atau dapat disimpulkan bahwa hampir semua item pertanyaan dinyatakan valid.

\section{Uji Reabilitas}

Dengan menggunakan rumusan reliabilitas dari Alpha Cronbach tersebut, maka didapat hasil bahwa pernyataan nilai alpha if item deleted seluruhnya menunjukkan reliabel, karena nilai 10 item pernyataan lebih besar dari 0,672.

\section{Uji Hipotesis Perhitungan Pengaruh Pengawasan Pungutan Retribusi (X) terhadap Kinerja Pegawai Retribusi (Y)}


Perhitungan pengaruh antara variabel Pengawasan Pungutan Retribusi (X) terhadap variabel kinerja pegawai retribusi (Y) pada Dinas Pasar Kota Bandar Lampung menggunakan hasil perhitungan melalui program SPSS 21 untuk uji statistik adalah sebagai berikut :

\section{Tabel 1.}

Uji Hipotesis Pengaruh Pengawasan Pungutan Retribusi terhadap Kinerja Pegawai Retribusi

\begin{tabular}{|c|c|c|c|c|c|c|c|}
\hline \multirow[t]{2}{*}{ Model } & \multicolumn{2}{|c|}{$\begin{array}{l}\text { Unstandar } \\
\text { ized } \\
\text { Coeficient } \\
\text { s }\end{array}$} & \multirow{2}{*}{$\begin{array}{c}\text { Standar } \\
\text { ized } \\
\text { Coefici } \\
\text { ents } \\
\text { Beta }\end{array}$} & \multirow[t]{2}{*}{$\mathrm{t}$} & \multirow[t]{2}{*}{ sig } & \multicolumn{2}{|c|}{$\begin{array}{c}95 \% \\
\text { Confidence } \\
\text { Inerval for } \\
\text { B }\end{array}$} \\
\hline & $\mathrm{B}$ & $\begin{array}{l}\text { Std. } \\
\text { Err } \\
\text { or }\end{array}$ & & & & $\begin{array}{c}\text { Lo } \\
\text { wer } \\
\text { Bou } \\
\text { nd }\end{array}$ & $\begin{array}{l}\text { Upp } \\
\text { er } \\
\text { Bou } \\
\text { nd }\end{array}$ \\
\hline 1 & .15 & 1.9 & .953 & .078 & .9 & .3 .8 & 4.14 \\
\hline (Constant & 4 & 76 & & 20.1 & 38 & 37 & 5 \\
\hline ) & .99 & .04 & & 77 & .0 & .891 & 1.08 \\
\hline $\begin{array}{l}\text { Pengemba } \\
\text { ngan }\end{array}$ & 0 & 9 & & & 00 & & 9 \\
\hline
\end{tabular}

Sumber : Data diolah, 2020

Berdasarkan hasil Uji t didapat nilai $\mathrm{t}$ hitung $=20,177$. Apabila dibandingkan dengan $\mathrm{t}$ tabel pada taraf signifikan 95\% yaitu 2,66, maka $\mathrm{t}$ hitung $=20,177>\mathrm{t}$ tabel $=$ 2,66 sehingga dapat disimpulkan bahwa : Ha yang menyatakan terdapat pengaruh antara variabel Pengawasan Pungutan Retribusi (X) terhadap Kinerja Pegawai Retribusi (Y) dapat diterima. Jadi variabel Pengawasan Pungutan Retribusi (X) berpengaruh terhadap variabel Kinerja Pegawai Retribusi (Y).

\section{Hasil Uji Determinasi $\left(\mathbf{R}^{\mathbf{2}}\right)$}

Sedangkan berdasarkan hasil penelitian, diperoleh koefisien determinasi Pengawasan Pungutan Retribusi terhadap kinerja pegawai retribusi dalah sebagai berikut :

Tabel 2

Koefisien Determinasi Pengawasan Pungutan Retribusi terhadap Kinerja Pegawai Retribusi.

\begin{tabular}{|c|c|c|c|c|c|c|c|c|c|}
\hline \multirow{6}{*}{$\begin{array}{l}\text { Mo } \\
\text { del }\end{array}$} & \multirow[t]{6}{*}{$\mathrm{R}$} & \multirow{4}{*}{$\begin{array}{c}\mathrm{R} \\
\mathrm{Sq} \\
\text { uar }\end{array}$} & \multirow{5}{*}{$\begin{array}{l}\text { Adj } \\
\text { uste } \\
\text { d R } \\
\text { Squ } \\
\text { are }\end{array}$} & \multirow{2}{*}{$\begin{array}{l}\text { Std. } \\
\text { Erro }\end{array}$} & \multicolumn{5}{|c|}{ Change Statistics } \\
\hline & & & & & $\mathrm{R}$. & $\mathrm{F}$ & $\mathrm{d}$ & $\mathrm{d}$ & Sig. \\
\hline & & & & $r$ of & Squ & Cha & $\mathrm{f}$ & f & $\mathrm{F}$ \\
\hline & & & & the & are & nge & 1 & 2 & Cha \\
\hline & & & & Esti & Cha & & & & nge \\
\hline & & & & mat & nge & & & & \\
\hline
\end{tabular}

\begin{tabular}{rrrrrrrrrr}
\multicolumn{10}{c}{$\mathrm{e}$} \\
\hline 1 & .9 & .90 & .906 & 1.10 & .90 & 407. & 1 & 4 & .00 \\
& 53 & 9 & & 020 & 9 & 119 & & 1 & 0
\end{tabular}

a. Predictors : (Constant). Pengembangan Organisasi

b. Dependent Variabel : Kinerja Karyawan

Koefisien Determinasi $=\mathrm{R}^{2}=$ $0,953^{2}=0,909=0,909 \times 100=90,9 \%$.

Dapat disimpulkan bahwa variabel Pengawasan Pungutan Retribusi menjelaskan variasi perubahan terhadap variabel Kinerja Pegawai Retribusi pada Dinas Pasar Kota Bandar Lampung sebesar $90,9 \%$, sedangkan sisanya dijelaskan oleh faktor lain yang tidak dikadi dalam penelitian ini.

\section{Hasil Uji Persamaan Linear}

Persamaan regresi antara variabel Pengawasan Pungutan Retribusi (X) terhadap variabel Kinerja Pegawai Retribusi (Y) adalah $\mathrm{Y}=0,154+0,990 \mathrm{X}$ penjelasannya adalah :

Bo $=0,154$ merupakan nilai konstanta atau yang dapat diartikan bahwa Pengawasan Pungutan Retribusi bernilai konstan, maka bila setiap terjadi peningkatan nilai pada variabel Pengawasan Pungutan Retribusi sebesar satu point, berakibat kinerja pegawai retribusi hanya akan meningkat sebesar $0,154 \%$.

$\mathrm{Bx}=0,990$ yang dapat dinyatakan bahwa setiap penambahan tanggapan responden mengenai Pengawasan Pungutan Retribusi, maka dapat diikuti oleh peningkatan kinerja pegawai retribusi sebesar $99,0 \%$ atau setiap terjadi peningkatan nilai pada variabel Pengawasan Pungutan Retribusi sebsar satu point, maka kinerja pegawai retribusi akan meningkat sebesar 0,990 point

Perhitungan diatas menggunakan derajat kebebasan $($ d.b $)=\mathrm{N}-\mathrm{K}$ pada nilai kepercayaan $(95 \%)$. Apabila $\mathrm{t}$ hitung $>\mathrm{t}$ tabel maka Ho ditolak yang berarti ada pengaruh antara variabel bebas dengan variabel terikat 


\section{KESIMPULAN}

Berdasarkan penelitian tentang Pengawasan Pungutan Retribusi Pasar Terhadap Kinerja Pegawai Retribusi menunjukan hasil bahwasanya terdapat pengaruh pengawasan pungutan retrribusi pasar terhadap Kinerja Pegawai Retribusi ditunjukan dari hasil Uji t didapat nilai $\mathrm{t}$ hitung $=20,177$. Apabila dibandingkan dengan $\mathrm{t}$ tabel pada taraf signifikan 95\% yaitu 2,66, maka $\mathrm{t}$ hitung $=20,177>\mathrm{t}$ tabel $=2,66$.

\section{DAFTAR PUSTAKA}

Alhaksbi, Leo. 2015. "STRATEGI OPTIMALISASI PENERIMAAN RETRIBUSI PASAR DI KABUPATEN ROKAN HILIR." JOM FISIP 2(2):15.

Datu, Christian, Harijanto Sabijono, and Christa Najoan. 2016. "Analisis Sistem Pemungutan Dan Penyetoran Retribusi Pasar Pada Dinas Perindustrian Perdagangan Koperasi Dan Penanaman Modal Kota Kotamobagu." Jurnal Riset Ekonomi, Manajemen, Bisnis Dan Akuntansi 4(1):1107-17. doi: 10.35794/emba.v4i1.11858.

Elim, Inggriani, David Saerang, and Dessy Toduho. 2014. "Penerimaan Retribusi Pasar Dalam Upaya Meningkatkan Pendapatan Asli Daerah Kota Tidore Kepulauan." Jurnal Riset Ekonomi, Manajemen, Bisnis Dan Akuntansi 2(2):1090 1103. doi: 10.35794/emba.v2i2.4501.

Mafaza, Wildah, Yuniadi Mayowan, and Tri Henri Sasetiadi. 2016. "Kontribusi Pajak Daerah Dan Retribusi Daerah Dalam Pendapatan
Asli Daerah." Jurnal Perpajakan (JEJAK) 11(1):1-4.

Mustakim, Senen, and Nur'aeni. 2020. "PENGARUH GAYA KEPEMIMPINAN DAN MOTIVASI KERJA TERHADAP KINERJA PEGAWAI BADAN PENGELOLAAN KEUANGAN DAN ASET DAERAH PROVINSI LAMPUNG." Jurnal Imu Manajemen Saburai 6(2):111-20. doi: 10.2991/aebmr.k.210121.019.

Putriani, Dian, and Parjiyana. 2017. "Analisis Pelaksanaan Pemungutan Retribusi Kebersihan Kota Pekanbaru." 3(1):42-65.

Rajab, Abdul. 2020. "Kontribusi Retribusi Pasar Terhadap Pendapan Asli Daerah Di Kabupaten Mamuju." Jurnal Ilmiah Ekonomi Pembangunan 1(2).

Sukmarwati, Armediana. 2013. “ANALISIS KINERJA PEGAWAI DI KECAMATAN GUNUNGPATI Jurusan Administrasi Publik Fakultas Ilmu Sosial Dan Ilmu Politik Universitas Diponegoro." Analisis Kinerja Pegawai Di Kecamatan Gunungpati Kota Semarang (ANALISIS):1-8.

Suprihati. 2014. "Analisis Faktor-Faktor Yang Mempengaruhi Kinerja Karyawan Perusahaan Sari Jati Di Sragen." 12(01). 